\title{
An Actor Network Approach to Informing Clients through Portals
}

\author{
Arthur Tatnall and Bill Davey \\ Victoria University and RMIT University, Melbourne, Australia
}

\section{Arthur.Tatnall@vu.edu.au Bill.Davey@rmit.edu.au}

\begin{abstract}
Portals are often seen as an appropriate method of informing clients. A problem of all web based solutions to informing clients is that the web is passive: clients must come to the web site. Approaches to research into use of portals are usually socio-technical, with common use of statistical techniques applied to survey results. Here we argue, informed by two detailed cases, that an actor network theory approach yields better results, more efficiently, when the case involves a number of small businesses being the clients. Alternative theories such as diffusion theories, based on the work of Rodgers and others, are more applicable when large, statistical effects are being anticipated.
\end{abstract}

Keywords: Web portals, technological innovation, innovation translation, small business, actornetwork theory.

\section{Introduction}

The problem of informing clients is, by its very nature, a socio-technical one. While researchers in computer science may choose to concentrate on a study of aspects of computer hardware and software alone, the business of informing systems is how people interact with and use computerbased systems. Information systems are complex socio-technical entities involving both human and non-human components(Tatnall \& Gilding, 1999). Systems analysts, designers, programmers, end-users, managers, PCs, mainframes, software, data and operating systems are only some of the many heterogeneous components of an information system. Research into the implementation and operation of information systems needs to take this heterogeneity into account and find a way to give due regard to both the human and non-human aspects of these systems (Tatnall, 2003).

If we are to create a system to inform clients we must engender change in the clients. They must first be drawn into a new system of communication, probably including a technology or system that they see as an innovation. The implementation of an information system, or the upgrading of an existing system, should be viewed in terms of technological innovation. The word 'innovation' is synonymous with 'newness' and 'change' (Dutch, 1962), and an innovation can be described as an idea that is perceived to be new to a particular person or group of people (Rogers, 1995). As

Material published as part of this journal, either on-line or in print, is copyrighted by Informing Science. Permission to make digital or paper copy of part or all of these works for personal or classroom use is granted without fee provided that the copies are not made or distributed for profit or commercial advantage AND that copies 1) bear this notice in full and 2) give the full citation on the first page. It is permissible to abstract these works so long as credit is given. To copy in all other cases or to republish or to post on a server or to redistribute to lists requires specific permission from the publisher at Publisher@InformingScience.org almost all information systems implementations fit this description it is quite appropriate to make use of innovation theory when researching these systems. This paper describes a research approach, based on actornetwork theory (Callon \& Latour, 1981; Latour, 1986; Law \& Callon, 
1988), used to investigate specific innovations in the design and implementation of portals for small to medium enterprises (SME). We cite results from two such studies to draw conclusions about the ability of actor network theory approaches to help us understand the situation when we are attempting to use a portal in informing clients. The two cases were studied from their inception, through growth, to their eventual end. In both cases an attempt was made by a central organisation to use a portal to provide information dissemination to small businesses, who were members of an organisation.

\section{The Bizewest Portal Project}

In June 2000 the Western Melbourne Region Economic Development Organisation (WREDO), a not-for-profit organisation sponsored by the six municipalities that make up the western region of Melbourne, received a Victorian government grant for a project to set up a business-to-business portal. The project was to create a horizontal portal, Bizewest, that would enable SMEs in Melbourne's west to engage in an increased number of e-Commerce transactions with each other. The western region of Melbourne contains around 20,000 businesses and is regarded as the manufacturing, transport and distribution hub of south-eastern Australia (Tatnall \& Burgess, 2002).

The main objective of the project, in its initial stages, was to encourage small to medium enterprises in Melbourne's west to be more aggressive in their up-take of e-Commerce business opportunities, and to encourage them to work with other local enterprises in the region also using the portal. The project was to create a true business-to-business portal on which on-line trading was to occur. It was also intended to encourage and facilitate transactions between local government and small business. The plan was to gain the participation of about three hundred SMEs from the local region in the use of the portal to facilitate their business-to-business and business to local government interactions. Another important project goal was youth involvement and students from the local high schools and colleges who were studying information technology (IT) related subjects, were to be given the opportunity to 'consult' with SMEs on a one-to-one basis in the development of their Web pages for the portal.

\section{The Australian Industry Group Portal}

The Australian Industry Group is an organisation formed for the benefit of its member companies, all of whom are small to medium sized manufacturing companies. The portal was designed to be both horizontal - between members themselves, and vertical between the members and the central organisation. The portal project was implemented so that members were to find each other as customers or suppliers of products, and use the portal to gain information about the industry in general. Potential users (those members with communication technologies in the workplace) amounted to more than 200,000 business across Australia.

Initially the project (Moussi \& Davey, 2001) identified a small group of members whose companies were added to the portal. The project then attempted to interest all members using the consultants from the group who regularly visited members. There was no attempt to provide higher level functionality, such as trading systems, through the portal. The main use was to be contact and communication. A search engine formed a major part of the software employed.

\section{Actor-Network Theory and Research on the B-B Portals}

While many approaches to research in technological areas treat the social and the technical in entirely different ways, actor-network theory (ANT) instead suggests a socio-technical account in which neither social nor technical positions are privileged. ANT deals with the social-technical divide by denying that purely technical or purely social relations are possible, and considers the world to be full of hybrid entities (Latour, 1993) containing both human and non-human ele- 
ments. Actor-network theory developed around problems associated with attempts to handle 'socio-technical imbroglios' (Latour, 1993) like electric cars (Callon, 1986a), supersonic aircraft (Law \& Callon. 1988), Kodak and the mass market for amateur photography (Latour. 1991) and a new railway system in Paris (Latour. 1996) by regarding the world as heterogeneous (Chagani. 1998). The utilisation of heterogeneous entities (Bijker, Hughes \& Pinch, 1987) then avoids questions of: 'is it social?' or 'is it technical?' as missing the point, which should be: "is this association stronger or weaker than that one?" (Latour, 1988. p. 27).

ANT offers this notion of heterogeneity to describe projects such as the portal projects discussed in this paper in which local semi-government organisations, industry groups, Internet service providers (ISP) and computer software companies build portals for use by SMEs. The projects involve not just these entities, but also many non-human entities such as computers, modems, telephone lines, Web development tools, and human entities including local business proprietors from small and medium-sized enterprises, customers, programmers, development managers, industry group personnel and local government staff. An information systems researcher using an actor-network approach would concentrate on issues of network formation, investigating the human and non-human actors and the alliances and networks they build up (Tatnall, 2000; Tatnall \& Gilding, 1999). This researcher would concentrate on the negotiations that allow the network to be configured by the enrolment of both human and non-human allies, and would consider any supposed characteristics of the technology only as network effects resulting from association. Each actor is itself also a simplified network (Law, 1992) and in ANT interactions and associations between actors and networks are the important thing, and actors are seen only as the sum of their interactions with other actors and networks.

\section{Actor-Network Theory and Essentialism}

A simplistic view of the portals would have it that businesses make their adoption decisions primarily because of the portal's characteristics, and would miss other influences due to interbusiness interactions and the backgrounds of the people involved. Using an essentialist approach like this to the research, the researcher may begin by outlining all the characteristics of portals and all the advantages and problems associated with their use, and then go on to suggest that the adoption, or rejection, of this technology by the local businesses was due largely to these characteristics. While this is likely to be partially true, it is unlikely to provide the complete explanation. The nature and size of each SME, the inter-business interactions in which they currently engage, the vigour and persuasiveness with which the local government authority and the industry organisation advocated their portals, and the backgrounds and interests of particular individuals in each of the small or medium businesses are also likely to have had an important affect that would, most likely, be ignored by the essentialist approach.

\section{Identification of Actors and Networks}

The main advice on method suggested by the proponents of actor-network theory is to "follow the actors" (Callon, 1986a, 1991; Latour, 1996) and to let them set the framework and limits of the study themselves. Latour (1996) likens this to a murder mystery novel in which questions are asked of each of the actors, and any subsequent directions and leads that may emerge from these initial questions are followed up by the detective. Some of these leads will, of course, be to other actors who will suggest yet other actors, and so the process continues.

In the case of these business-to-business portals an actor-network researcher would begin by identifying some of the important actors, starting perhaps with the portal project managers. An interview with the project manager should reveal why the project was instigated and identify some of the other actors. One line of inquiry resulting from the interview with the project manager might be to approach the portal software designer and programmers. Another set of actors 
consists of the proprietors of the local businesses themselves, and the project manager may suggest some 'business champions' to interview first to find out why they had adopted the portal and what had influenced them in doing so. At least some of these business people might then point to the influence exerted by the computer hardware or software as a significant factor, so identifying some non-human actors. From this point on the key is to follow the actors, both human and nonhuman, searching out interactions, negotiations, alliances and networks. Negotiations between actors must be carefully investigated. Apart from the obvious human to human kind of negotiation must be included human to non-human interactions such as the business people trying to work out how the portal operates, and how to adapt this technology to their own business purposes. They negotiate with the portal software to see what it can do for them, and it negotiates with them to convince them to adopt its way of doing business. The process of adopting and implementing the portal is now seen as the complex set of interactions that it is, and not just the inevitable result of the innate characteristics of this technology.

\section{Actors, Networks and Black Boxes}

In actor-network theory an actor is a human or non-human entity that is able to make its presence individually felt (Law, 1987) by the other actors, but can in many ways also be thought of as a 'black box'(Callon, 1986a), the contents of which we can chose not to worry about. When investigating the portals it is convenient, most of the time, to consider things like the Internet service provider (ISP) and the portal software to constitute a black box. This means that this aspect of the technology can then be considered as just a single actor; the portal, and its interactions with other actors investigated on this basis. At other times it might be necessary to lift the lid of the black box and investigate the enclosed network of the ISP, telephone lines, computers, data storage, programmers and interface designers that it contains. The advantage of black-boxing is that most of the time the portal can be regarded as just another actor.

\section{Innovation Translation}

It is often the case that a small business which is considering some technological innovation is interested in only some aspects of this innovation and not others (Tatnall, 2001). In actor-network terms it needs to translate (Callon, 1986b) this piece of technology into a form where it can be adopted. This may mean choosing some elements of the technology and leaving out others, resulting in what is finally adopted not being the innovation in its original form, but a translation of it into a form that is suitable for use by the recipient small business (Tatnall, 2001). For the business-to-business portals, in actor-network terms the portals need to negotiate with each individual SME to determine how it could best be implemented by them. In other terms this could be seen as the portal's proponents negotiating with the SME proprietors, but it is really rather more than this as at this point we need to look inside the portals' black boxes to see what is happening there. Inside the black boxes the portals contain many components. When, in ANT terms we say that the SMEs negotiated with the portal we really mean that they engaged in interactions with all of these entities. It is just easier to speak of the portals as single actors than the complex networks they really are.

\section{Problematisation, Interessement, Enrolment and Mobilization}

Callon (1986b) outlines the process of translation as having four 'moments' the first of which he calls problematisation, or 'how to become indispensable', in which one or more key actors attempts to define the nature of the problem and the roles of other actors to fit the solution proposed. The problem is re-defined in terms of solutions offered by these actors who then attempt to establish themselves as an 'obligatory passage point' (Callon, 1986b) which must be negotiated as part of its solution. In the portal projects the problematisation proposed by its instigators and 
designers is that business-to-business interactions are best performed using a portal. For the project to be successful the portal must be seen by the proprietors of the SMEs as an obligatory passage point to business-to-business transactions. The second moment is interessement, or 'how allies are locked in place', and is a series of processes which attempt to impose the identities and roles defined in the problematisation on the other actors. It means interesting and attracting an actor by coming between it and some other actor (Law, 1986). In the case of the portals, proprietors of the SMEs need to be convinced that this technology is more worthwhile and offers them better business prospects than the approaches they now use. It must convince them to stop sending orders and requests for information by post or fax and instead to use the portal.

The third moment, enrolment or 'how to define and coordinate the roles' will then follow, leading to the establishment of a stable network of alliances. For enrolment to be successful however, it requires more than just one set of actors imposing their will on others; it also requires these others to yield (Singleton \& Michael, 1993). It is not enough for those promoting the portal to eloquently espouse its benefits, the SMEs must also give up their old methods of business-tobusiness transactions. Finally, mobilisation or 'are the spokespersons representative?' occurs as the proposed solution gains wider acceptance (McMaster, Vidgen \& Wastell, 1997) and an even larger network of absent entities is created (Grint \& Woolgar, 1997) through some actors acting as spokespersons for others. The portal can be judged to be truly successful when SME proprietors are advocating its advantages to each other. When looked at in this way the process of adopting, or choosing not to adopt the portal begins to be seen in its true complexity, not just as a yes/no decision, but as a complex set of negotiations between a number of human and non-human actors. The use of an actor-network approach like this makes the complexity apparent.

\section{The Analysis}

Interviews were used to identify actors and their relationship with the portals in initial stages. Interviews with various stakeholders involved in the Bizewest project included a particularly important group of five companies designated as 'business champions' for this project. Some of the issues considered important by several of these business champions are discussed below. One of the business champions was a medium-sized Melbourne company, with about 100 employees, that stores frozen food and transports it to supermarkets and other locations around the country. A major reason that this company adopted the portal was the hope that it would provide a better opportunity to deal with people in the local region (Tatnall \& Burgess, 2004). The general manager indicated that he thought it was going to provide benefits for everybody and not just his company. This was important to him. He could see use of the portal changing his business by enabling it to use people in the local region, and that "working together for the benefit of everybody" would be advantageous for the region (Cold Storage, 2001).

A firm of solicitors had also just started making use of the portal and were trying to work out the best ways to utilise it to advantage. Their primary goal was to use the portal to increase their visibility. "What we want is for people to discover something that they may not have recognised and that is that there is a top quality legal service in the Western Region that they can come to for most of their legal services." They had few specific expectations of the portal, but hoped later to allow businesses to register interest and gain some access to their legal services using the portal (Footscray Solicitors, 2001).

Another business champion was a small printer with 15 employees that had just begun using the portal. They saw the portal as having "fantastic possibilities" but there were currently some problems: "I suppose that people who are on the portal see us and they contact us, but there is something wrong with it at the moment. The problem is that they can't actually ring a quote with us. It has to be fixed up, but once it is fixed it will be good." (Printing Press, 2001). 
Finally, a textile company just outside the metropolitan area were using the portal mainly for promoting their image but did intend to move to B-B operations in the future. "I think that it will be inevitable, but not next month, it's still a year or two off. I'm uncertain of what the plan is at this point; there is no plan." One of the problems that this small business faced was lack of computing expertise. This is a common problem among small businesses (Burgess, 2002). Typically there are one or two people that know something about computers, but do not have much spare time to plan and implement these systems. "I think the way that we will go is like many businesses; we will dip our toe in the water and do some basic ordering: stationery that's a common one. We will choose to start the ball rolling, get our head around a few of the practical issues of that, and then on to bigger things." (Textile Company, 2001)

Table 1: Usage of the Bizewest Portal

\begin{tabular}{|l|c|c|c|}
\hline Month & Sessions & One Minute Sessions & One Page Sessions \\
\hline September 2002 & 2208 & $68.6 \%$ & $86.2 \%$ \\
\hline October 2002 & 3672 & $77.1 \%$ & $90.0 \%$ \\
\hline November 2002 & 2848 & $74.6 \%$ & $88.0 \%$ \\
\hline December 2002 & 2766 & $71.7 \%$ & $85.9 \%$ \\
\hline January 2003 & 2706 & $82.8 \%$ & $90.2 \%$ \\
\hline February 2003 & 2804 & $86.7 \%$ & $89.6 \%$ \\
\hline March 2003 & 2934 & $88.7 \%$ & $90.5 \%$ \\
\hline April 2003 & 2254 & $87.7 \%$ & $88.7 \%$ \\
\hline May 2003 & 2865 & $86.4 \%$ & $86.7 \%$ \\
\hline June 2003 & 2200 & $84.0 \%$ & $86.7 \%$ \\
\hline July 2003 & 78 & $75.6 \%$ & $85.9 \%$ \\
\hline
\end{tabular}

A study of the Bizewest portal in 2003 (Pliaskin \& Tatnall, 2005) showed that activity on the site was always extremely disappointing. The proportion of sessions that were one page hits and/or lasted for one minute or less seems to indicate that a large proportion of sessions were accidental or unintentional. Although a considerable number of businesses had taken up the offer and joined with Bizewest, many baulked when it was suggested that in future they would need to pay an annual fee to cover the costs of the software company hosting the portal. The problem was that the grant to set up the portal provided no funds for on-going maintenance and enhancement, and Bizewest was running out of money.

Similarly, interviews were conducted with the 'seeding' companies of the AIG portal. In both cases it was found that most businesses adopting the portal did so because it seemed to them to be 'a good idea' rather than because they had any clear idea of its benefits. Few had looked objectively at the characteristics of portal technology or business-to-business e-commerce. Common reason for adoption included: "If other businesses adopt it and we don't we will be left behind." "All the talk is about e-commerce and how it is the way of the future." "It doesn't look too hard to make it work and we have little to lose." and "My kids tell me that everyone will be on the Internet soon and we had better be too."

Work by Moussi and Davey (2001), showed that the demise of originally intended use of the AIG portal was steady over its first three years, with almost no activity, including that of the seeding companies. 


\section{Conclusion}

Preliminary results of the analysis of the Bizewest portal project have been reported previously (Pliaskin \& Tatnall, 2005; Tatnall \& Burgess, 2002). The original analysis showed that while the goal of the project was to revolutionize the way that SMEs communicated with each other in the local region, to attempt to change the culture of 300 businesses was a monumental task and Bizewest was probably doomed to failure right from the outset. Because the originating organisation has a good a lot of the businesses became involved because they were convinced that this was the way to go. They were not, however, willing to contribute money when they could not see any immediate tangible benefits and the portal floundered financially. In this study the success or failure of the portals depended upon individual companies taking up the technology. In many cases the technology is not a product that will be offered to the whole word, to be taken up by those liking it, but a technology offered to solve an information problem of a select group. The two cases here show that real understanding is efficiently achieved using actor network theory to identify those components (actors and interactions) peculiar to the case.

An actor-network approach to researching an information systems innovation such as the business-to-business portals described in this paper details the construction of networks and alliances to support and embed the changes it produces in order to make them durable. It does not look for simple answers involving reliance on properties of the technology to see why one technological innovation was taken up while another was not. Instead it looks for an explanation of the much more complex interactions and negotiations that take place between human and non-human actors. In a research project such as this a researcher who concentrated on the technology as the driving force, or one who ignored the affects of the technology and concentrated on the human and social interactions involved, would produce a very unbalanced account. In socio-technical situations like this where the contributions of both human and non-human actors are equally important, an approach like that offered by actor-network theory has, we contend, much to offer.

ANT is sometimes criticized as offering only 'after-the-fact' explanations of technology adoption, and there is some truth in this criticism. We suggest though, probably against the intention of the original designers of the ANT approach to technological innovation, that it may be possible for those interested in fostering the success of such an innovation to make use of actor-network concepts to make adoption more likely (Tatnall \& Davey, 2002, 2004). We suggest that if those attempting to implement a new technological solution note the need to involve all actors, and to gain their co-operation, then they might be able to steer the direction of things towards a greater likelihood of success. We leave a consideration of these ideas to our readers, and perhaps a later paper.

\section{References}

Bijker, W. E., Hughes, T. P. \& Pinch, T. J., Eds. (1987). The social construction of technological systems: New directions in the sociology and history of technology. Cambridge, MA: MIT Press.

Burgess, S. (2002). Information technology in small business: Issues and challenges. In S. Burgess (Ed.), Information technology and small business: Issues and challenges. Pennsylvania, USA, Idea Group.

Callon, M. (1986a). The sociology of an actor-network: The case of the electric vehicle. In M. Callon, J. Law\& A. Rip, (Eds.), Mapping the dynamics of science and technology (pp. 19-34.). London: Macmillan Press.

Callon, M. (1986b). Some elements of a sociology of translation: Domestication of the scallops and the fishermen of St Brieuc Bay. In J. Law (Ed.), Power, action \& belief. A new sociology of knowledge? (pp. 196-229). London: Routledge \& Kegan Paul.

Callon, M. (1991). Techno-economic networks and irreversibility. In J. Law (Ed.), A sociology of monsters. Essays on power, technology and domination (pp. 132-164). London: Routledge. 
Callon, M. \& Latour, B. (1981). Unscrewing the big leviathan: How actors macro-structure reality and how sociologists help them to do so. In K. Knorr-Cetina \& A. V. Cicourel (Eds.), Advances in social theory and methodology. Toward an integration of micro and macro-sociologies (pp. 277-303). London: Routledge \& Kegan Paul.

Chagani, F. (1998). Postmodernism: Rearranging the furniture of the universe. Irreverence, 1 (3), 1-3.

Cold Storage (2001). Private correspondence - Bizewest. Melbourne.

Dutch, R. A., Ed. (1962). Roget's Thesaurus. London: Longman.

Footscray Solicitors (2001). Private correspondence - Bizewest. Melbourne.

Grint, K. \& Woolgar, S. (1997). The machine at work - Technology, work and organisation. Cambridge: Polity Press.

Latour, B. (1986). The Powers of association. Power, action and belief. A new sociology of knowledge? Sociological Review monograph 32. Law, J. London, Routledge \& Kegan Paul: 264-280.

Latour, B. (1988). The prince for machines as well as for machinations. In B. Elliott (Ed.), Technology and social process (pp. 20-43). Edinburgh: Edinburgh University Press.

Latour, B. (1991). Technology is society made durable. In J. Law (Ed.), A sociology of monsters. Essays on power, technology and domination (pp. 103-131). London: Routledge.

Latour, B. (1993). We have never been modern. Hemel Hempstead: Harvester Wheatsheaf.

Latour, B. (1996). Aramis or the love of technology. Cambridge, MA: Harvard University Press.

Law, J. (1986). The heterogeneity of texts. In M. Callon, J. Law\& A. Rip, (Eds.), Mapping the dynamics of science and technology (pp. 67-83). UK: Macmillan Press.

Law, J. (1987). Technology and heterogeneous engineering: The case of Portuguese expansion. In W. E. Bijker, T. P. Hughes, \& T. J. Pinch (Eds.), The social construction of technological systems: New directions in the sociology and history of technology (pp. 111-134). Cambridge, MA: MIT Press.

Law, J. (1992). Notes on the theory of the actor-network: Ordering, strategy and heterogeneity. Systems Practice 5, (4), 379-393.

Law, J. \& Callon, M. (1988). Engineering and sociology in a military aircraft project: A network analysis of technological change. Social Problems, 35 (3), 284-297.

McMaster, T., Vidgen, R. T. \& Wastell, D. G. (1997). Towards an understanding of technology in transition. Two conflicting theories. Information Systems Research in Scandinavia, IRIS20 Conference, Hanko, Norway, University of Oslo.

Moussi, C. \& Davey, B. (2001). A continuum of electronic commerce maturity - from buying a computer to business transformation. Proceedings of the Twelfth Australasian Conference on Information Systems (ACIS 2001), Coffs Harbour, NSW, ACIS.

Pliaskin, A. \& Tatnall, A. (2005). Developing a portal to build a business community. In A. Tatnall (Ed.), Web portals: The new gateways to Internet information and services (pp. 335-348). Hershey, PA: Idea Group Publishing.

Printing Press (2001). Private correspondence - Bizewest. Melbourne.

Rogers, E. M. (1995). Diffusion of innovations. New York, The Free Press.

Singleton, V. \& Michael, M. (1993). Actor-networks and ambivalence: General practitioners in the UK cervical screening programme. Social Studies of Science, 23, 227-264.

Tatnall, A. (2000). Innovation and change in the information systems curriculum of an Australian university: a socio-technical perspective. PhD thesis. Education. Rockhampton, Central Queensland University. 
Tatnall, A. (2001). Adoption of information technology by small business - Two different approaches to modelling innovation. Managing Information Technology in a Global Economy - (IRMA'2001), Toronto, Canada, Idea Group Publishing.

Tatnall, A. (2003). Actor-network theory as a socio-technical approach to information systems research. In S. Clarke, E. Coakes, M. G. Hunter, \& A. Wenn (Eds.), Socio-technical and human cognition elements of information systems (pp. 266-283). Hershey, PA: Information Science Publishing.

Tatnall, A. \& Burgess, S. (2002). Using actor-network theory to research the implementation of a B-B portal for regional SMEs in Melbourne, Australia. 15th Bled Electronic Commerce Conference - 'eReality: Constructing the eEconomy', Bled, Slovenia, University of Maribor.

Tatnall, A. \& Burgess, S. (2004). Using actor-network theory to identify factors affecting the adoption of ecommerce in SMEs. In M. Singh, \& D. Waddell (Eds.), E-Business: Innovation and change management (pp. 152-169). Hershey, PA: Idea Group Publishing.

Tatnall, A. \& Davey, B. (2002). Information systems curriculum development as an ecological process. In E. Cohen (Ed.), IT education: Challenges for the 21st century (pp. 206-221). Hershey, PA: Idea Group Publishing.

Tatnall, A. \& Davey, B. (2004). Improving the chances of getting your IT curriculum innovation successfully adopted by the application of an ecological approach to innovation. Informing Science, 7, 87-103.

Tatnall, A. \& Gilding, A. (1999). Actor-network theory and information systems research. 10th Australasian Conference on Information Systems (ACIS), Wellington, Victoria University of Wellington.

Textile Company (2001). Private correspondence - Bizewest. Melbourne.

\section{Biographies}

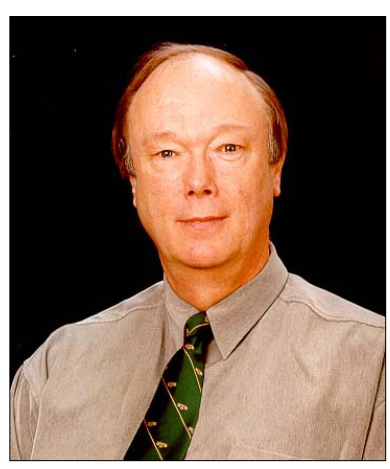

Arthur Tatnall is an Associate Professor in the Graduate School of Business at Victoria University in Melbourne, Australia. He holds bachelors degrees in Science and Education, a Graduate Diploma in Computer Science, and a research Master of Arts in which he explored the origins of Information Systems curriculum in Australian universities. His PhD involved a study in curriculum innovation in which he investigated the manner in which Visual Basic entered the curriculum of an Australian university. His research interests include technological innovation, information systems curriculum, project management, electronic commerce, and information technology in educational management.

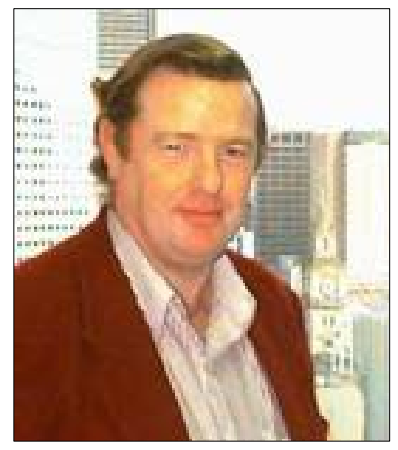

Bill Davey is a Senior Lecturer in the School of Business Information Technology at RMIT University, Melbourne, Australia. He holds bachelors degrees in Science and Education, a Graduate Diploma in Computing, and Master of Business degree. His research interests include methodologies for systems analysis and systems development, Visual Basic programming, information systems curriculum, and information technology in educational management.

Arthur and Bill have worked together co-operatively on many occasions. They have co-operated on several joint research projects and coauthored a large number of papers, book chapters, and textbooks relating to management information systems, programming, computers in management, and IS curriculum. 